\title{
Predictors of adverse pathologic features after radical prostatectomy in low-risk prostate cancer
}

\author{
Jae Won Park, Dong Hoon Koh, Won Sik Jang, Kang Su Cho, Won Sik Ham, Koon Ho Rha, Sung Joon Hong \\ and Young Deuk Choi id
}

\begin{abstract}
Background: Prostate-specific antigen (PSA) screening more frequently detects early stage prostate cancer (PC). However, adverse pathologic features (APFs) after radical prostatectomy (RP) in low-risk PC occur. Previous related studies had utilized outdated staging criteria or small sample cohorts. In this study, we analyzed predictors of APFs after RP in low-risk PC using classification under the current criteria.

Materials and methods: We retrospectively reviewed medical records of 546 low-risk PC patients who had undergone RP. Low-risk PC was defined as PC with clinical T1-T2a, Gleason score $\leq 6$, and PSA levels $<10 \mathrm{ng} / \mathrm{mL}$. Clinical and pathological parameters were analyzed to predict APFs. APFs were defined as extracapsular extension (ECE), seminal vesicle invasion (SVI), or positive surgical margins (PSM). We analyzed our data using univariable and multivariable logistic regression analyses, as well as receiver operator characteristics to predict APFs.
\end{abstract}

Results: Among 546 patients, ECE, SVI, and PSM were present in 199 (36.4\%), 8 (1.5\%), and 179 cases (32.8\%), respectively. PSM had a significant correlation with preoperative high PSA levels and number of positive cores obtained. ECE/SVI was also significantly correlated with PSA levels and number of positive cores. As a result, presence of APFs after RP was associated with high PSA levels and large number of positive cores. PSA $>4.5 \mathrm{ng} / \mathrm{mL}$ and number of positive cores $>2$ in low-risk PC were significantly associated with APFs, and suggested as cut-off values for predicting APFs.

Conclusions: PSA $>4.5 \mathrm{ng} / \mathrm{mL}$ and number of positive cores $>2$ in low-risk PC were associated with presence of APFs and patients with such records should be considered carefully to provide active surveillance.

Keywords: Low-risk prostate cancer, Adverse pathologic features, Needle biopsy, Radical prostatectomy

\section{Background}

Prostate cancer (PC) is the most common type of newly diagnosed malignancy in males [1] and it accounts for nearly $30 \%$ of all diagnosed male cancers [2]. As PC screening by measuring prostate-specific antigen (PSA) levels has become more widespread, the proportion of PC presenting with low-risk factors has also increased. Therefore, ways to manage this disease have changed significantly [3]. Although initial therapy for PC is determined by risk classification, all treatment options can have negative impacts on the patient's quality of life [4].

\footnotetext{
* Correspondence: youngd74@yuhs.ac

Department of Urology, Urological Science Institute, Yonsei University College of Medicine, 50-1, Yonsei-ro, Seodaemun-gu, Seoul 120-752, South
} Korea

(c) The Author(s). 2018 Open Access This article is distributed under the terms of the Creative Commons Attribution 4.0 International License (http://creativecommons.org/licenses/by/4.0/), which permits unrestricted use, distribution, and reproduction in any medium, provided you give appropriate credit to the original author(s) and the source, provide a link to the Creative Commons license, and indicate if changes were made. The Creative Commons Public Domain Dedication waiver (http://creativecommons.org/publicdomain/zero/1.0/) applies to the data made available in this article, unless otherwise stated.

Over-diagnosing and over-treating have thus become major concerns for urologists, especially in regards to low-risk PC [5].

Radical prostatectomy (RP) is a commonly accepted treatment option; however, the possibility of complications during surgical process is a considerable risk factor. Although introduction of robotic surgery has provided significant improvements in outcomes, the risks for urinary incontinence and sexual dysfunction still exist $[6,7]$. For now, active surveillance (AS) is being considered for select patients with low-risk, organ-confined PC [2]. Several standards have also been proposed to assess the utility of AS [8]. However, in some studies, patients with lowrisk $\mathrm{PC}$, who were eligible for AS, showed adverse pathologic features (APFs) after RP $[9,10]$. Despite stringent 
selection of only low-risk PC, only a quarter of AS patients had pathologically insignificant PC [10]. Even in the low-risk PC group, PC patients with APFs after RP should be considered for adjuvant radiotherapy [11] and these patients should avoid under-treatment. There have been several reports which propose criteria to predict worse pathologic outcome; however, predictors for APFs in lowrisk PC group by current criteria are limited. In this study, we aimed to investigate predictors for APFs following RP in the low-risk PC group.

\section{Methods}

Data were collected after approval from the Institutional Review Board at Yonsei University College of Medicine (No. 4-2017-0492). Authors retrospectively reviewed medical records of 4440 patients who underwent RP from 1992 to 2014. RP was performed by multiple surgeons using open or robot-assisted laparoscopic techniques. After exclusion of patients with incomplete medical records and those who received neoadjuvant therapy, patients were classified for preoperative risk group according to $\mathrm{NCCN}^{\circ}$ guidelines. Low-risk $\mathrm{PC}$ was defined as PC with clinical T1-T2a, Gleason score (GS) $\leq 6$, and PSA levels $<10 \mathrm{ng} / \mathrm{mL}$. Grading system was used according to the 2005 International Society of Urological Pathology (ISUP) Consensus [12]. TNM stage was determined according to the American Joint Committee on Cancer's 8th edition TNM staging system.

According to our selection criteria, 546 patients with low-risk PC were included in this study. Data for these patients included age, body mass index (BMI), type of operation, preoperative PSA, prostate volume measured by transrectal ultrasonography (TRUS), number of prostate biopsy cores taken, number of positive cores observed, percentage of positive cores, and pathologic characteristics of specimens following RP. Maximal percentage in each biopsy core was defined as the highest percentage of tumor present in each individual biopsy core. All pathologic diagnosis was performed by expert pathologists. Biopsy specimens obtained from outside of our hospital were reviewed by our pathologists. The primary endpoint was occurrence of APFs after RP in lowrisk PC group. APFs were defined as extracapsular extension (ECE), seminal vesicle invasion (SVI), and positive surgical margin (PSM) [13]. Tumor volume, which was defined as the combined volume of all nodules, was calculated using a grid method [14].

Univariable and multivariable logistic regression analyses were performed on clinical parameters to investigate predictors for APFs following RP in our low-risk PC cohort. In addition, clinical predictors for each type of APF were also analyzed. Receiver operator characteristics (ROC) curve analysis was performed to determine optimal cut-off value via area under curve (AUC).
Youden's Index in ROC curves was used to select an optimal cutoff value of related parameters for predicting APFs. All statistical analysis was performed out using SPSS Statistics software version 23.0 (IBM, Armonk, NY, USA).

\section{Results}

Baseline characteristics of patients in the study group are displayed in Table 1. Median age for patients was 64 years (Interquartile range [IQR] 59-69). Median prostate volume, as measured by TRUS, was $24.1 \mathrm{ml}$ (IQR 25-42), and median PSA level was $5.6 \mathrm{ng} / \mathrm{mL}$ (IQR 4.5-7.0). Median number of biopsy cores taken was 12

Table 1 Baseline characteristics

\begin{tabular}{|c|c|c|}
\hline Variables $(n=546)$ & Median & $\mathrm{IQR}$ \\
\hline Age, year & 64 & $59-69$ \\
\hline $\mathrm{BMI}, \mathrm{kg} / \mathrm{m} 2$ & 24.1 & $22.3-25.7$ \\
\hline \multicolumn{3}{|l|}{ Year of operation (n/\%) } \\
\hline$\sim 2005$ & 46 & 8.4 \\
\hline $2006 \sim 2009$ & 365 & 66.8 \\
\hline $2010 \sim 2014$ & 135 & 24.7 \\
\hline \multicolumn{3}{|l|}{ Type of operation (n/\%) } \\
\hline Open & 146 & 26.7 \\
\hline Robotic & 400 & 73.3 \\
\hline Prostate volume measured by TRUS, ml & 31.0 & $25.0-42.0$ \\
\hline PSA, ng/ml & 5.6 & $4.5-7.0$ \\
\hline Number of biopsy core & 12 & $12-12$ \\
\hline Number of positive core & 2 & $1-3$ \\
\hline Percentage of positive core, $\%$ & 16.7 & $8.3-25.0$ \\
\hline Maximal percentage in each biopsy core, \% & 30.0 & $10.0-50.0$ \\
\hline Prostate volume in specimen, $\mathrm{ml}$ & 33.0 & $26-41.1$ \\
\hline Tumor volume in specimen, $\mathrm{ml}$ & 0.8 & $0.3-1.8$ \\
\hline Tumor / Prostate ratio & 0.03 & $0.01-0.06$ \\
\hline Extracapsular extension (n/\%) & 199 & 36.4 \\
\hline Seminal vesicle invasion (n/\%) & 8 & 1.5 \\
\hline Positive surgical margin (n/\%) & 179 & 32.8 \\
\hline \multicolumn{3}{|l|}{ GS after radical prostatectomy (n/\%) } \\
\hline GS $6(3+3)$ & 336 & 61.5 \\
\hline GS $7(3+4)$ & 143 & 26.2 \\
\hline GS $7(4+3)$ & 48 & 8.8 \\
\hline GS $8(4+4)$ & 13 & 2.4 \\
\hline GS 9 or 10 & 6 & 1.1 \\
\hline GS upgrading (n/\%) & 210 & 38.5 \\
\hline Perineural invasion (n/\%) & 175 & 32.1 \\
\hline Lymphovascular invasion (n/\%) & 12 & 2.2 \\
\hline HGPIN (n/\%) & 308 & 56.4 \\
\hline
\end{tabular}

$\mathrm{BMI}=$ Body mass index; $\mathrm{GS}=$ Gleason score; $\mathrm{HGPIN}=$ High grade prostatic intraepithelial neoplasia; PSA = Prostate specific antigen;

TRUS = Transrectal ultrasonography 
(IQR 12-12) with a median number of two positive cores (IQR 1-3). Median percentage of positive cores was $16.7 \%$ (IQR 8.3-25.0). Additionally, median maximal percentage in each positive core was $30.0 \%$ (IQR 10.0 50.0). Median tumor volume of specimens following RP was $0.8 \mathrm{ml}$ (IQR 0.3-1.8). ECE was present in 199 cases (36.4\%), and surgical margins were involved in 179 cases (32.8\%). Invaded seminal vesicles were observed in eight cases (1.5\%). No lymph node metastasis was reported. GS was upgraded in 210 cases (38.5\%). Among them, upgrading to GS $7(3+4)$ was most common upgrade (68.1\%). Furthermore, GS above 8 was also reported in 19 cases $(3.5 \%)$. Perineural invasion was reported in 175 cases $(32.1 \%)$ and lymphovascular invasion was present in 12 cases $(2.2 \%)$. PC with high grade prostatic intraepithelial neoplasia was observed in 308 cases (56.4\%).

Univariable and multivariable logistic regression analyses were performed with each clinical parameter for APFs and each component of APFs. While performing univariable and multivariable logistic regression analyses for PSM and PSA levels, number of positive cores was included as covariates in multivariable logistic regression model. A positive association was determined by PSA levels (hazard ratio [HR] 1.14, 95\% confidence interval [CI 1.03-1.25) and number of positive cores (HR 1.12, 95\% CI 1.01-1.24), as reported in Table 2.

According to the logistic regression analysis which included PSA level, number and percentage of positive cores and maximal percentage in each positive cores as covariates, ECE/SVI was also significantly associated with PSA levels (HR 1.21, 95\% CI 1.09-1.33) and number of positive cores (HR 1.38, 95\% CI 1.23-1.56), as reported in Table 3. Age, BMI, type of operation, and prostate volumes measured by TRUS were not associated with adverse outcomes.

PSA levels showed a significant correlation with presence of APFs (HR 1.21, 95\% CI 1.10-1.33) when analyzed for integrated APFs by same regression analysis model, and number of positive cores was also correlated with worse pathologic outcomes (HR 1.33, 95\% CI 1.17-1.50), as reported in Table 4.

ROC curve analysis was used to determine optimal cutoff value by Youden Index in Fig. 1. Optimal cut-off value for PSA levels, which can predict APFs, was determined to be $4.5 \mathrm{ng} / \mathrm{mL}$, with AUC of 0.61 (95\% CI 0.56-0.66). We determined the optimal cutoff value for number of positive cores above 2, which estimated an AUC of 0.62 (95\% CI 0.57-0.66). If we considered both parameters to predict APFs, it would have shown slightly better outcomes for predictions in Additional file 1: Figure S1. $(\mathrm{AUC}=0.66)$.

\section{Discussion}

$\mathrm{PC}$ has been known as one of the most common cancer types in newly diagnosed population, and the thirdleading cause of death in males [1]. Proportion of lowrisk $\mathrm{PC}$ has increased, and treatment options for $\mathrm{PC}$ are known to differ by risk classification [3]. However, substantial variation in treatment exists in the management of localized PC. Localized PC has been treated by not only RP, but also by external beam radiation and AS [15]. Due to concerns of over-diagnosis and overtreatment, AS is considered especially in cases of low-risk localized PC [16]. AS has become one of the treatment options for low-risk PC, under the current $\mathrm{NCCN}^{\oplus}$ guidelines [11].

However, in previous studies, APFs were noted after $\mathrm{RP}$ even in low-risk PC cases [10, 17]. Beauval et al. reported that only $26 \%$ of patients had "insignificant" PC after RP, out of 919 total patients eligible for AS. They reported that $12.5 \%$ of patients had extraprostatic extensions, and GS was upgraded in $34 \%$ of patients [10]. Simon et al. investigated pathologic outcomes of $1097 \mathrm{PCs}$ in candidates for AS. Of these patients, $7 \%$ to $19 \%$ had ECE, and $2 \%$ to

Table 2 Univariable and Multivariable analysis of factors associated with PSM

\begin{tabular}{lll}
\hline & Univariable & Multivariable \\
\hline Age & $H R(95 \% \mathrm{Cl})$ & 0.64 \\
BMI & $1.01(0.98-1.03)$ & 0.58 \\
Type of operation & $1.02(0.95-1.09)$ & \\
$\quad$ & & 0.16 \\
$\quad$ Open & $1($ ref $)$ & 0.53 \\
$\quad$ Robotic & $1.35(0.89-2.04)$ & $<0.01$ \\
Prostate volume measured by TRUS & $1.00(0.99-1.02)$ & 0.01 \\
PSA & $1.15(1.05-1.27)$ & 0.05 \\
Number of positive biopsy core & $1.14(1.03-1.26)$ & 0.01 \\
Percentage of positive biopsy core & $1.01(1.00-1.02)$ & $1.14(1.03-1.25)$ \\
Maximal percentage in each positive core & $1.00(0.99-1.01)$ & $1.12(1.01-1.24)$ \\
\hline
\end{tabular}

$\mathrm{BMI}=$ Body mass index; PSA = Prostate specific antigen; PSM = Positive surgical margin; TRUS = Transrectal ultrasonography 
Table 3 Univariable and Multivariable analysis of factors associated with ECE/SVI

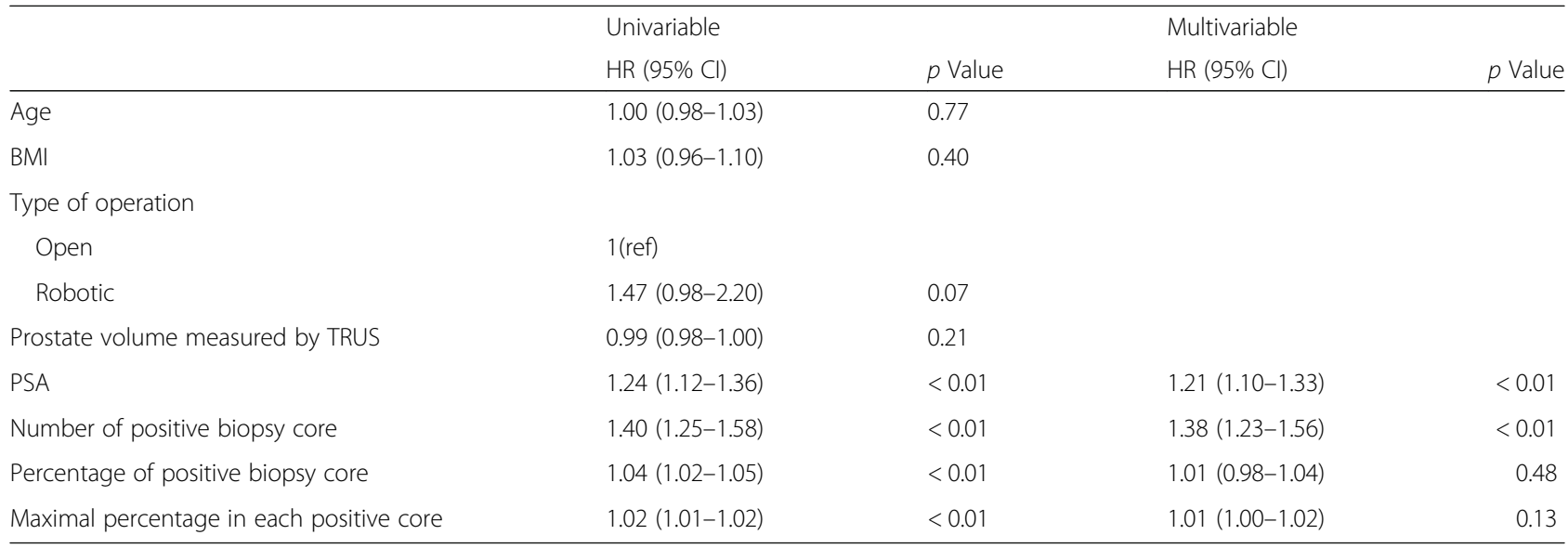

$\mathrm{BMI}=$ Body mass index; $\mathrm{ECE}=$ Extracapsular extension; PSA = Prostate specific antigen; SVI=Seminal vesicle invasion; TRUS = Transrectal ultrasonography;

9\% had SVI [17]. Having PSM was also associated with poor prognosis when analyzed for recurrence-free survival and the need for salvage therapy. Ploussard et al. reported that five-year recurrence-free survival occurred in $57.5 \%$ of cases with PSM, compared to $84.4 \%$ of cases with negative margins [18]. Therefore, prediction of APFs is important in low-risk PC patients who are eligible for AS. In our study, approximately $36 \%$ of patients had tumor extension through prostate capsule, and $32 \%$ of patients reported PSM (Table 1).

Patients with APFs should be considered for adjuvant radiotherapy after RP [13]. Bolla et al. studied long term results in a randomized controlled trial for postoperative irradiation after RP in 1005 high-risk PC patients. They observed biochemical recurrence (BCR) in $39.4 \%$ of patients who received adjuvant therapy, compared to 61 . $8 \%$ in the observation group. Patients who underwent postoperative irradiation showed improvements in biochemical progression-free survival rates and local tumor control (EORTC trial 22,911) [19]. Additionally,
Swanson et al. evaluated a cohort of 719 patients for pathologic findings and risk of failure. They suggested that patients with any of the following factors were candidates for adjuvant therapy: ECE, SVI, or margin involvement [20]. Therefore, physicians should offer adjuvant therapy to patients with APFs observed at RP [13]. Patients with APFs should consult with both urologist and radiation oncologist for more complete treatment information [21].

Based on these findings, many researchers have investigated predictors for APFs necessitating adjuvant therapy in low-risk PC patients. Although some recent studies discovered new biomarkers for predicting PC aggressiveness [22, 23], these biomarkers have not been widely used in clinical practice yet.

Prostate biopsy yields information on not only the presence of cancer, but also GS, histological subtype, and additional clinical parameters, including number and percentage of positive cores. In a previous study, Gao et al. investigated pathologic outcomes of 62 low-

Table 4 Univariable and Multivariable analysis of factors associated with APFs

\begin{tabular}{|c|c|c|c|c|}
\hline & \multicolumn{2}{|l|}{ Univariable } & \multicolumn{2}{|l|}{ Multivariable } \\
\hline & HR (95\% Cl) & $p$ Value & HR $(95 \% \mathrm{Cl})$ & $p$ Value \\
\hline Age & $1.01(0.99-1.03)$ & 0.40 & & \\
\hline $\mathrm{BMI}$ & $1.05(0.98-1.12)$ & 0.17 & & \\
\hline \multicolumn{5}{|l|}{ Type of operation } \\
\hline Open & 1 (ref) & & & \\
\hline Robotic & $1.36(0.93-2.00)$ & 0.11 & & \\
\hline Prostate volume measured by TRUS & $1.00(0.99-1.02)$ & 0.44 & & \\
\hline PSA & $1.23(1.13-1.35)$ & $<0.01$ & $1.21(1.10-1.33)$ & $<0.01$ \\
\hline Number of positive biopsy core & $1.35(1.19-1.52)$ & $<0.01$ & $1.33(1.17-1.50)$ & $<0.01$ \\
\hline Percentage of positive biopsy core & $1.03(1.02-1.05)$ & $<0.01$ & $1.01(1.98-1.04)$ & 0.43 \\
\hline Maximal percentage in each positive core & $1.01(1.00-1.02)$ & $<0.01$ & $1.01(1.00-1.01)$ & 0.29 \\
\hline
\end{tabular}




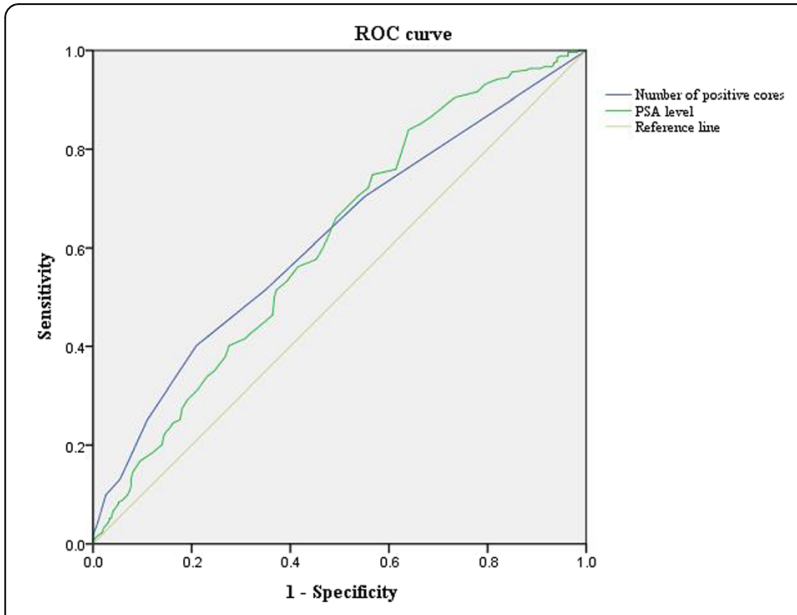

Fig. 1 Receiver operator characteristics (ROC) curve of PSA levels and number of positive cores for predicting presence of adverse pathologic features

risk PC patients with PSA levels $\leq 10 \mathrm{ng} / \mathrm{mL}$, biopsy GS $\leq$ 7, and clinical cT1c-T2b. They suggested that number of positive biopsy cores was associated with PSM [24]. Ogawa et al. investigated predictors for organ confined $\mathrm{PC}$ in 54 patients who underwent RP for T1c PC and reported that PSA levels and number of positive cores were independent predictors for organ confined tumor [25]. However, previous studies included a relatively small number of patients, which could cause limitation in predicting APFs. Our results support these findings by demonstrating a significant association between number of positive cores to PSM and pathologic upstaging (Tables 2 and 3). Number of positive cores is known to be associated not only with PSM or upstaging, but also with GS upgrading following RP. Hong et al. investigated 203 patients with low-risk PC defined by D'Amico classification and 81 patients were upgraded to GS $\geq 7$ after RP. They reported preoperative PSA levels and number of positive cores were independent predictors of GS score upgrading after RP [26]. However, they included only upgrading of GS for their results, and not for predictors of upstaging or PSM.

Our findings are similar to those of previous studies which showed associations between APFs and number of positive cores observed. However, the criterion for classification of low-risk PC has become stricter after these studies were published. Current criteria include not only preoperative PSA levels, but also biopsy GS and clinical $\mathrm{T}$ stage [11, 27]. Furthermore, low-risk PC is stratified as low-risk and very low-risk PC, based on these clinical variables $[2,11]$. Therefore, previous studies utilized outdated staging criteria, in addition to having relatively small sample cohorts and had limited clinical information to suggest cutoff values for predicting APFs in low-risk PC.
We included patients over a wide range of period from 1992 to 2014. However, most of the patients (91.5\%) had undergone RP within 2006 to 2014. Therefore, we used the 2005 ISUP grading system for PC. Due to limitations of pathologic reviews of old specimen slides, we could not re-review the slides before 2005. ISUP Consensus was newly introduced in 2014 [28], and further validations will be followed according to the new grading system. Meanwhile, predictive performance of ROC curve was relatively weak in our study, which may be due to limitations of having subjects with PSA $<10 \mathrm{ng} / \mathrm{ml}$ or limited number of biopsy cores taken.

Our study had several limitations. First, it was retrospective review performed at single institution; therefore, multi-center, prospective studies are still needed. Second, biopsy protocol was not standardized as there were many patients who did not undergo prostate biopsy at our institution. Though most patients had 12 core biopsies, there were some patients with fewer than 12 core biopsies. Third, low-risk PC has been re-classified more specifically, with the very low-risk PC category added in the latest guidelines [11]. However, in this study, very low-risk PC showed no significant difference in reporting APFs after RP, compared to low-risk PC. Last, presence of APFs was the primary endpoint of this study. We did not perform an analysis for long term survival of these patients. Long term data should be followed to confirm the lasting impact of APFs on low-risk PC.

Despite these limitations, our study remains informative for clinicians who treat patients with low-risk PC. For now, clinical APF predictors that recommended adjuvant therapy are lacking, especially in low-risk PC, as classified by current criteria. This is the largest study to date to investigate predictors for APFs in low-risk PC, as defined by current staging criteria, considering how using both the number of positive cores and PSA levels better predict APFs than by PSA levels alone. In addition, this study determined the optimal cut-off value to predict APFs in preoperative clinical practice. These parameters could predict APFs in low-risk PC, which is classified by factors such as low PSA, GS, and T stages, without additional cost, all of which may serve as essential information before surgical treatment. These findings offer supplemental information to avoid undertreatment of patients. Randomized studies are needed to further confirm our findings. We also anticipate more precise diagnostic tools to become available through gene analysis in the near future, to further accurately diagnose and treat $\mathrm{PC}$.

\section{Conclusions}

PSA $>4.5 \mathrm{ng} / \mathrm{mL}$ and number of positive cores $>2$ in low-risk PC was associated presence of APFs and these patients should be considered carefully to provide active 
surveillance. Physicians should be aware of these parameters, which can predict APFs, and should avoid undertreatment of these patients.

\section{Additional file}

Additional file 1: Figure S1. Receiver operator characteristics (ROC) curve of PSA levels, number of positive cores and multivariable logistic regression model incorporating PSA levels and number of positive cores for predicting presence of adverse pathologic features. If we considered both parameters to predict APFs, it would have shown slightly better outcomes for predictions (AUC = 0.662). (JPG $31 \mathrm{~kb}$ )

\section{Abbreviations}

APFs: adverse pathologic features; AS: active surveillance; AUC: area under curve; BMl: body mass index; ECE: extracapsular extension; GS: Gleason score; PC: prostate cancer; PSA: prostate-specific antigen; PSM: positive surgical margins; ROC: receiver operator characteristics; RP: radical prostatectomy; SVl: seminal vesicle invasion; TRUS: transrectal ultrasonography

\section{Authors' contribution}

JWP made substantial contributions to study conception and design, data analysis and interpretation, and was involved in drafting the manuscript. DHK and WSJ made substantial contributions to data analysis and interpretation, and was involved in revising the manuscript critically for important intellectual content. KSC, WSH, KHR and SJH made substantial contributions to data acquisition. YDC supervised the study, helped to draft the manuscript and was involved in revising it critically for important intellectual content. All authors read and approved the final manuscript.

\section{Availability of data and materials}

The datasets used or analyzed during the current study are available from the corresponding author on reasonable request.

\section{Ethics approval and consent to participate}

All procedures in our study involving human participants were performed in accordance with the ethical standards of the institutional and/or national research committee, and with the 1964 Helsinki declaration and its later amendments or comparable ethical standards. For this type of study, formal consent is not required. Data were collected after approval from the Institutional Review Board at Yonsei University College of Medicine (No. 4-2017-0492).

\section{Competing interests}

There are no competing interests in conducting the current research.

\section{Publisher's Note}

Springer Nature remains neutral with regard to jurisdictional claims in published maps and institutional affiliations.

Received: 20 December 2017 Accepted: 20 April 2018

Published online: 09 May 2018

References:

1. Siegel RL, Miller KD, Jemal A. Cancer statistics, 2017. CA Cancer J Clin. 2017; 67(1):7-30.

2. Cooperberg MR, Broering JM, Kantoff PW, Carroll PR. Contemporary trends in low risk prostate cancer: risk assessment and treatment. J Urol. 2007;178(3 Pt 2):S14-9.

3. Cooperberg MR, Lubeck DP, Meng MV, Mehta SS, Carroll PR. The changing face of low-risk prostate cancer: trends in clinical presentation and primary management. J. Clin. Oncol. Off. J. Am. Soc. Clin. Oncol. 2004;22(11):2141-9.

4. Wei JT, Dunn RL, Sandler HM, McLaughlin PW, Montie JE, Litwin MS, Nyquist L, Sanda MG. Comprehensive comparison of health-related quality of life after contemporary therapies for localized prostate cancer. J. Clin. Oncol. Off. J. Am. Soc. Clin. Oncol. 2002;20(2):557-66.

5. Bangma $\mathrm{CH}$, Roemeling $\mathrm{S}$, Schroder FH. Overdiagnosis and overtreatment of early detected prostate cancer. World J Urol. 2007;25(1):3-9.
6. Rocco B, Matei DV, Melegari S, Ospina JC, Mazzoleni F, Errico G, Mastropasqua M, Santoro L, Detti S, de Cobelli O. Robotic vs open prostatectomy in a laparoscopically naive Centre: a matched-pair analysis. BJU Int. 2009;104(7):991-5.

7. Willis DL, Gonzalgo ML, Brotzman M, Feng Z, Trock B, Su LM. Comparison of outcomes between pure laparoscopic vs robot-assisted laparoscopic radical prostatectomy: a study of comparative effectiveness based upon validated quality of life outcomes. BJU Int. 2012;109(6):898-905.

8. Suardi N, Capitanio U, Chun FK, Graefen M, Perrotte P, Schlomm T, Haese A, Huland $\mathrm{H}$, Erbersdobler A, Montorsi $\mathrm{F}$, et al. Currently used criteria for active surveillance in men with low-risk prostate cancer: an analysis of pathologic features. Cancer. 2008;113(8):2068-72.

9. Isariyawongse BK, Sun L, Banez LL, Robertson C, Polascik TJ, Maloney K, Donatucci C, Albala D, Mouraviev V, Madden JF, et al. Significant discrepancies between diagnostic and pathologic Gleason sums in prostate cancer: the predictive role of age and prostate-specific antigen. Urology. 2008;72(4):882-6.

10. Beauval JB, Ploussard G, Soulie M, Pfister C, Van Agt S, Vincendeau S, Larue S, Rigaud J, Gaschignard N, Roupret M, et al. Pathologic findings in radical prostatectomy specimens from patients eligible for active surveillance with highly selective criteria: a multicenter study. Urology. 2012;80(3):656-60.

11. National Comprehensive Cancer Network (NCCN ${ }^{\oplus}$ ) clinical practice guidelines in Oncology. Prostate cancer, version 2.2017 [https://www.nccn. org/professionals/physician_gls/pdf/prostate.pdf].

12. Epstein Jl, Allsbrook WCJ, Amin MB, Egevad LL. Committee at|G: the 2005 International Society of Urological Pathology (ISUP) consensus conference on Gleason grading of prostatic carcinoma. Am J Surg Pathol. 2005;29(9): $1228-42$

13. Thompson IM, Valicenti RK, Albertsen P, Davis BJ, Goldenberg SL, Hahn C, Klein E, Michalski J, Roach M, Sartor O, et al. Adjuvant and salvage radiotherapy after prostatectomy: AUA/ASTRO guideline. J Urol. 2013;190(2): 441-9.

14. Shin SJ, Park CK, Park SY, Jang WS, Lee JY, Choi YD, Cho NH. Total intraglandular and index tumor volumes predict biochemical recurrence in prostate cancer. Virchows Archiv : an international journal of pathology. 2016:469(3):305-12.

15. Cooperberg MR, Broering JM, Carroll PR. Time trends and local variation in primary treatment of localized prostate cancer. J. Clin. Oncol. Off. J. Am. Soc. Clin. Oncol. 2010;28(7):1117-23.

16. Soloway MS, Soloway CT, Eldefrawy A, Acosta K, Kava B, Manoharan M. Careful selection and close monitoring of low-risk prostate cancer patients on active surveillance minimizes the need for treatment. Eur Urol. 2010;58(6):831-5.

17. Conti SL, Dall'era M, Fradet V, Cowan JE, Simko J, Carroll PR. Pathological outcomes of candidates for active surveillance of prostate cancer. J Urol. 2009:181(4):1628-33. discussion 1633-1624

18. Ploussard G, Agamy MA, Alenda O, Allory Y, Mouracade P, Vordos D, Hoznek A, Abbou CC, de la Taille A, Salomon L. Impact of positive surgica margins on prostate-specific antigen failure after radical prostatectomy in adjuvant treatment-naive patients. BJU Int. 2011;107(11):1748-54.

19. Bolla M, van Poppel H, Tombal B, Vekemans K, Da Pozzo L, de Reijke TM, Verbaeys A, Bosset JF, van Velthoven $\mathrm{R}$, Colombel $\mathrm{M}$, et al. Postoperative radiotherapy after radical prostatectomy for high-risk prostate cancer: longterm results of a randomised controlled trial (EORTC trial 22911). Lancet (London, England). 2012;380(9858):2018-27.

20. Swanson GP, Riggs M, Hermans M. Pathologic findings at radical prostatectomy: risk factors for failure and death. Urol Oncol. 2007;25(2):110-4.

21. Kim SP, Tilburt JC, Karnes RJ, Ziegenfuss JY, Han LC, Shah ND, Frank I, Smaldone MC, Gross CP, Yu JB, et al. Variation in treatment recommendations of adjuvant radiation therapy for high-risk prostate cancer by physician specialty. Urology. 2013;82(4):807-12.

22. Klein EA, Cooperberg MR, Magi-Galluzzi C, Simko JP, Falzarano SM, Maddala T, Chan JM, Li J, Cowan JE, Tsiatis AC, et al. A 17-gene assay to predict prostate cancer aggressiveness in the context of Gleason grade heterogeneity, tumor multifocality, and biopsy undersampling. Eur Urol. 2014;66(3):550-60

23. Cuzick J, Berney DM, Fisher G, Mesher D, Moller H, Reid JE, Perry M, Park J Younus A, Gutin A, et al. Prognostic value of a cell cycle progression signature for prostate cancer death in a conservatively managed needle biopsy cohort. Br J Cancer. 2012;106(6):1095-9.

24. Gao X, Mohideen N, Flanigan RC, Waters WB, Wojcik EM, Leman CR. The extent of biopsy involvement as an independent predictor of extraprostatic 
extension and surgical margin status in low risk prostate cancer: implications for treatment selection. J Urol. 2000;164(6):1982-6.

25. Ogawa O, Egawa S, Arai Y, Tobisu K, Yoshida O, Kato T. Preoperative predictors for organ-confined disease in Japanese patients with stage T1c prostate cancer. International journal of urology : official journal of the Japanese Urological Association. 1998:5(5):454-8.

26. Hong SK, Han BK, Lee ST, Kim SS, Min KE, Jeong SJ, Jeong H, Byun SS, Lee $\mathrm{HJ}$, Choe G, et al. Prediction of Gleason score upgrading in low-risk prostate cancers diagnosed via multi ( $>$ or $=12$ )-core prostate biopsy. World J Urol. 2009;27(2):271-6.

27. D'Amico AV, Whittington R, Malkowicz SB, Schultz D, Blank K, Broderick GA, Tomaszewski JE, Renshaw AA, Kaplan I, Beard CJ, et al. Biochemical outcome after radical prostatectomy, external beam radiation therapy, or interstitial radiation therapy for clinically localized prostate cancer. JAMA. 1998;280(11):969-74

28. Epstein Jl, Egevad L, Amin MB, Delahunt B, Srigley JR, Humphrey PA. The 2014 International Society of Urological Pathology (ISUP) consensus conference on Gleason grading of prostatic carcinoma: definition of grading patterns and proposal for a new grading system. Am J Surg Pathol. 2016;40(2):244-52

Ready to submit your research? Choose BMC and benefit from:

- fast, convenient online submission

- thorough peer review by experienced researchers in your field

- rapid publication on acceptance

- support for research data, including large and complex data types

- gold Open Access which fosters wider collaboration and increased citations

- maximum visibility for your research: over $100 \mathrm{M}$ website views per year

At BMC, research is always in progress.

Learn more biomedcentral.com/submissions 